\title{
AL MARGEN DE LOS MANUSCRITOS DE LOS SUEÑOS: LA HUELLA DEL LECTOR CONTEMPORÁNEO
}

Pasos de un peregrino son errante (Luis DE Góngora, Soledad I)

El estudio de los manuscritos de los Sueños me ha llevado por sus diversas tierras, unas más y otras menos acogedoras de quien entra, a veces sin guía y con poca luz, en busca de aquella coherencia y humanidad que es el arte. Discurrir por páginas copiadas hace siglos pero que han descansado mudas, perdidas en alguna biblioteca caritativa, supone entrar a solas en la vida accidentada de un texto literario. ¿Y si en aquel terreno se topara con la huella de otro lector? Esta es la experiencia humana que mi propia peregrinación ofrece al lector actual.

Conocemos los perfiles de las polémicas que suscitó la obra de Góngora, y sabemos cómo y por qué gozaron las obras de Cervantes gran popularidad entre los lectores de su siglo. Sin embargo, los numerosísimos manuscritos e impresos quevedianos sugieren que el autor más leído en la España del siglo xvn era Quevedo: mucho más que cualquier otro, incluso Cervantes. Y los Sueños ocuparon un lugar preeminente en su obra ${ }^{1}$.

Pero no quiero hablar de polémicas ni de teorías, ni de la estadística de las ediciones, sino de una realidad más personal: ¿Qué

I Sobre la popularidad de Cervantes, véase el estudio excelente de Daniet. E. Quilter, The image of the "Quijote" in the seventeenth century, tesis inédita, Universidad de Illinois, Urbana, 1962. Sobre la popularidad de Quevedo, véase en el mismo estudio las pp. 16-18, "Table I: The distribution of editions of literary works in seventeenth-century Spain". Por ejemplo, entre 1595 y 1704 se publicaron unas 50 ediciones de las diversas obras de Cervantes, 49 de Ginés Pérez de Hita, 45 de Juan Pérez de Montalbán, 38 de Gracián, y 175 de Quevedo. Todo autor y todo libro parecen gozar de un cierto momento de mayor popularidad: a Cervantes le corresponden los años 1605-1630 (34 ediciones); a Alemán, 1599-1625 (24 ediciones); a Montalbán, 1625-1650 (23 ediciones); y a Quevedo, en este último período, 123 ediciones. En los cinco años iniciales de su publicación (1626-1631) aparecieron 55 ediciones de las obras de Quevedo, La cifra correspondiente a Cervantes es 15, y aún menor para otros autores. 
valores humanos buscaban en los Sueños tantos y tan ávidos lectores? ¿Y qué satisfacciones personales y resonancias de su propia experiencia encontraron en estas sátiras de Quevedo? Creo que ciertas notas que aparecen en los márgenes de los manuscritos, nacidas del fervor de la lectura, secuestradas de los ojos espulgadores de la Censura y desconocidas hasta hoy, revelan experiencias de lecturas tan diversas como ricas. Y nos recuerdan las palabras de Quevedo en un bello soneto sobre el acto creativo de leer: podemos con nuestros ojos oír hablar a los lectores ${ }^{2}$.

Hace pocos años descubrió mi buen amigo George Haley los papeles manuscritos de Girolamo da Sommaia, un literato italiano que estudió derecho en Salamanca de 1602 a 1607. El contenido quevediano de este material lo analizó Haley en un hermoso estudio, del cual hemos entresacado los datos que siguen sobre Da Sommaia ${ }^{3}$. El 22 de abril de 1605, prestó Juan Solórzano Pereyra su copia manuscrita del "Sueño del Juicio final" a Da Sommaia. Tañto le interesaba el Sueño a éste, que el mismo día encargó a su amanuense una copia para sí. El día siguiente, 23 de abril, de. volvió el manuscrito primitivo a Solórzano, y prestó el nuevo a Gil González Dávila. Llevaba Da Sommaia un diario, y en un período de cuatro meses a lo largo del verano de 1605, anota entre una semana y otra los nombres de doce lectores del "Juicio Final". Uno de ellos fue Francisco de Oviedo, probablemente el mismo sujeto que más tarde fue secretario del Rey, con quien mantuvo Quevedo abundante correspondencia al final de su vida, y al cual nombró como uno de sus albaceas. Pertenecían otros lectores al círculo universitario y literario, bien conocidos algunos, como Solórzano y González Dávila, y otros de menos renombre, como Juan Velázquez, Catedrático de Simples. Prestáronse entre sí copias manuscritas del Sueño, y más de una vez coincidieron en un mismo día la devolución de una copia prestada y el nuevo préstamo a otro lector; alguna vez el amigo se marchó de Salamanca sin devolver la copia, y el dueño tenía que buscar otro original y encargar nueva copia.

Los datos de Da Sommaia se limitan a una sola ciudad, y son mínimos. Identifica cinco copias que llegaron a sus manos; sin embargo, cuando anota la devolución de una que había prestado, no dice si el nuevo lector había encargado otra para su uso, de manera que no sabemos cuántas copias en total encargaron los doce lecto-

2 "Retirado en la paz destos desiertos, / em pocos pero doctos libros juntos, / bibo con el comerzio de difuntos / i con mis ojos oigo hablar los muertos". Texto autógrafo reproducido en nuestro libro, En torno a la poesia de Quevedo, Madrid, 1967, p. 26.

3 Gforge Haley, "The earliest dated manuscript of Quevedo's Sueño del juicio final", MPh 67 (1970), 238-262. 
res anotados. Es más: registra Da Sommaia sólo los lectores a quienes prestó una copia. ¿Cuántos otros hubo que tuvieron en préstamo ejemplares distintos del de Da Sommaia?, y de ellos, ¿cuántos encargaron a su vez copias que ya se han perdido?

Sugieren los datos de Da Sommaia que el "Sueño del Juicio final" fue escrito en 1604 o 1605, cuando asistía Quevedo a la Universidad de Valladolid. Coinciden estos años con la estancia de la corte en aquella ciudad, y abundan los testimonios de una estimable actividad literaria. ¿A cuántos lectores y poetas les llegó una copia del Sueño de Quevedo? De las cinco copias mencionadas por Da Sommaia, existe hoy una sola. Justamente con las otras doce que actualmente se conservan del "Juicio final", suman trece de las que ninguna parece ser copia directa de cualquier otra entre las restantes. Seguramente se habrán perdido muchísimas más, y con ellas el testimonio del interés intenso de los lectores por estas obras.

A los datos recogidos por Haley deben agregarse los de las notas que hemos estudiado. Por ejemplo, uno de los mss. fue copiado en Valencia, el 3 de mayo de 1613, según afirma su portada (véase lámina 1). En esta ciudad hubo bastante actividad literaria; ¿allí gozaron los Sueños una popularidad análoga a la de Salamanca? Por lo demás, indica la referida portada que el interés por los Sueños no se limitó a los años inmediatos a su creación, pues todavía en 1613 se hacían copias de obras escritas en 1605 y poco después. Por otra parte, ya hemos mencionado que en cierta ocasión se quejó Da Sommaia porque un amigo se marchó de Salamanca sin devolver el ejemplar que le había prestado. Tal aspecto de la expansión de los Sueños resulta documentalmente ilustrado por el ms. de Valencia, pues indica una nota al margen que fue leído posteriormente en Salamanca ${ }^{4}$.

Los papeles de Da Sommaia aportan datos sobre otro aspecto de la reproducción de los Sueños. El lector que quería poseer una copia, generalmente la encargaba a un amanuense. Algunos de estos escribientes solían corregir ciertas erratas sobre la marcha; otros, al acabar la tarea, la repasaban y corregían; y a veces algún dueño o lector corrigió la copia que su amanuense acababa de preparar.

De las tres clases de correcciones ofrece numerosos ejemplos la copia que encargó Girolamo Da Sommaia a su amanuense, Simón Danti (véase lámina 2), y también presentan ejemplos algunos de

4 En nuestra edición de la versión manuscrita de los Sueños, ya en prensa, se describen y localizan todos los manuscritos que conocemos y se transcriben todas las variantes que arrojan. El manuscrito firmado en Valencia es el 93 de la Biblioteca de Menéndez Pelayo (Santander); la portada se encuentra en el f. Ir (foliación en números arábigos), y la nota en el f. 16r (lo comentamos a continuación). 
los otros mss. de los Sueños. El copista de un ms. del "Sueño del Infierno" corrigió doce palabras singulares y subsanó una omisión extensa; después, vino otra persona y corrigió 110 palabras singulares, subsanó cinco omisiones extensas, y agregó al margen tres notas de erudición clásica (véase lámina 3). La extensión de los pasajes suplidos sugiere que fueron copiados de otro ms., y, en efecto, existe hoy uno que coincide palabra por palabra con lo suplido. Pero no quiero acumular documentación ni clasificar correcciones, sino rastrear motivos y características personales. En términos humanos, se nos ha presentado el dueño de un ms., o el lector, tan preocupado por la pureza de aquel ejemplar del "Infierno" que se afanó por conseguir otro (¿prestado?), cotejarlo o hacerlo cotejar palabra por palabra con el suyo, y en corregir un número crecido de palabras y pasajes deficientes ${ }^{5}$.

En tales términos humanos quisiéramos examinar otras tantas anotaciones de distintas personas, esperando precisar así los valores artísticos y humanos que encontraron ellas en los Sueños, y esperando también vislumbrar los criterios y el carácter de cada lector o lectura. Nuestro criterio es humano y estético; por lo tanto, no trata de ser absolutamente comprehensivo, y excluye los detalles que no nos conduzcan a la interpretación de aquellos valores humanos y estéticos. Procedamos a individualizar los autores de las anotaciones, empezando con un ms. cuyos márgenes revelan cinco lecturas o revisiones distintas por cuatro personas. Para distinguirlas entre sí, nos hemos valido de la letra de cada nota y del color de la tinta; para establecer las revisiones sucesivas de una misma persona, nos hemos fundado en el color de la tinta. Quede sentado que no podemos asegurar que todas las notas de una misma letra y escritas con una sola tinta, corresponden a idéntico momento: puede suceder que el individuo haya escrito ciertas notas con cierta tinta, y haya vuelto a usarla en otra ocasión para nuevas anotaciones. Parece menos probable que una misma persona haya redactado una serie de notas empleando dos tintas diferentes ${ }^{6}$.

Contiene este ms. una copia del "Alguacil endemoniado" (ff. Ir$6 v$ ), seguido del "Juicio final" (ff. 7r-12v), y del "Infierno" (ff. 15r-36r), todos copiados por una misma mano y con una misma

5 El manuscrito corregido es el 10387 de la Biblioteca Nacional de Madrid, ff. 246r-284v; el que sirvió de fuente para los pasajes deficientes es el 109 de la Biblioteca de Menéndez Pelayo (o quizá un antepasado, si no descendiente suyo). Todas las mencionadas correcciones y adiciones se registran en el aparato crítico de nuestra edición de los Sueños.

6 Agradezco profundamente a mi buen amigo Felipe C. R. Maldonado el examen que hizo en Santander del color de las tintas, así como de la lectura de algunas palabras que no quedaron claras en el microfilm. Se trata del manuscrito 109 de la Biblioteca de Menéndez Pelayo, ff. 1-36r. 
tinta de color rojizo relativamente intenso. De la misma mano y tinta se encuentra una serie de 23 correcciones y notas, que denominamos serie $A$. Algunas de las correcciones de esta serie se hicieron sobre la marcha: al escribir una palabra, el amanuense la tachó o enmendó en el acto y luego siguió copiando el texto. Por ejemplo, en el prólogo al lector del "Alguacil" afirma el autor que los escritores no deben temer la crítica negativa de los ignorantes, porque éstos, "no pueden decir mal, sabiendo que si lo dicen de lo malo, lo dicen de sí mismos, y si de lo [tachado: malo] bueno, saben todos que no lo entienden". No hay nada interlineado ni al margen: todo está en una misma línea, lo cual indica que escribió el copista la palabra "malo", se dio cuenta en el acto de su error, la tachó y siguió copiando.

En la serie $A$ que examinamos, hay cinco correcciones hechas igualmente sobre la marcha. Otras trece figuran entre líneas o al margen, lo cual indica que se escribieron cuando ya estaban copiadas las palabras inmediatas. Puede ocurrir que se escribieran momentos después, o al acabar la copia del folio, o todavía más tarde en una revisión posterior. De las trece, una es muy extensa (nueve palabras tachadas en el texto, y veinte agregadas al margen), y concuerda la enmienda con la versión de todos los demás mss. que conocemos, lo cual sugiere que fue copiada de otro texto, o del mismo que servía de modelo en una revisión posterior, pero no que fue inventada por la persona que lo corrigió (véase lámina 4). Sugieren lo mismo otras seis enmiendas de ciertas palabras que no eran errores tan obvios como para corregirse sin consultar otro ms. (y en efecto, la enmienda de cada uno coincide con los otros mss. que se conocen hoy en día). Por ejemplo, hay en el "Alguacil endemoniado" un pasaje extenso de sátira contra los poderosos, pero en el lugar de las dos referencias explícitas a los reyes, dice el ms. "ricos", palabra que fue luego corregida al margen de acuerdo con todos los otros mss.: "reies" (ff. 4v, 5r).

Las notas restantes de la serie $A$ están compuestas por tres citas en latín y dos notas explicativas en español. Las tres citas dan la impresión de alguna erudición, y de cierta mentalidad académica (reza una: "Hoc ex Seneca in epist. ad Lucil.", f. 6v). Tal impresión se comprueba en una de las dos notas explicativas, que ilustra un pasaje sobre el Bosco: "Gerónimo [tachado: Pintor] Bosco, Pintor, retrató en pinturas macarrónicas, como las poesías de Merlín Cocalo [sic], los vicios de los hombres, pintando varios asuntos, de donde dijeron, Los disparates de Gerónimo Bosco. Achácanle de hereje sin raçón. Véase Sigüença, pte. 3, lib. 4, discurs. 17, pág. 837" (f. $4 v$ ). La otra nota aclara un chiste sobre ciertos papeles que llevaba al infierno un maestro de esgrima. Dice el texto: "Sacando 
otros papeles, dijo [el maestro] que aquéllos eran los testimonios de sus haçañas; y caiéronsele en el suelo, y fueron a lebantarlos dos diablos y un alguacil, y él los lebantó primero que los diablos". A cierto lector contemporáneo de este ms. o de un antepasado suyo, ya fuera el dueño, el amanuense u otro, le pareció que el chiste presentaba dificultades para su recta inteligencia, pues puso al margen esta nota: "El alguacil lebantó los testimonios antes que los diablos, por ser testimonios" (f. 9v).

Para resumir, el copista de este ms. fue suficientemente consciente de su tarea como para darse cuenta de ciertos errores y corregirlos sobre la marcha, y se mostró lo bastante interesado como para corregir otros en una revisión posterior, o a la vista de otro ejemplar (quizá por orden del dueño del ms.). Nos enseñan las tres citas $y$ las dos anotaciones que este texto, o un antepasado suyo, fue leído por una persona de cierta erudición y de mentalidad académica. Por último, y quizá sea lo más significativo, nos enseña que los chistes y las elipsis de Quevedo ofrecían dificultades de interpretación aun para los lectores cultos de la época.

A juzgar por el color de la tinta, parece que después de copiar el texto y las notas de la serie $A$, volvió el mismo amanuense a la tarea, e incorporó a este ms. otra serie de notas, empleando una tinta rojiza menos intensa que la usada para el texto y la serie $A$. No sabemos quien fuera el autor de aquellas anotaciones, ni siquiera podemos aventurar si las series $A$ y $B$ corresponden a una persona o a dos. La serie $A$ se ocupa más del "Alguacil" y "Juicio" (19 de las 23 notas), pero la serie $B$ versa casi totalmente sobre el "Infierno" (40 de las 43 notas). En $B$, la proporción de correcciones de errores se reduce ( 15 de las 43 , en contraste con 18 de las 23 de $A$ ); no hay ninguna enmienda echa sobre la marcha, se aumentan las citas eruditas (18), y las aclaraciones del texto (9). Igual que en la serie $A$, delatan algunas de las notas de $B$ una mentalidad académica; por ejemplo, ésta sobre los zurdos: "Cum antea Q. Mutius diceretur inde Scaeuola dictus est, quod sinistra vteretur. Graeci enim $\Sigma$ xalos vocant quos nostrates çurdos" (f. 26r; hay también algunas notas todavía más extensas en los ff. $25 \mathrm{r}$ y $30 \mathrm{r}$, y por supuesto las 18 citas eruditas).

En la serie $A$ hemos observado que ciertos chistes provocaban comentarios aclaratorios por parte de un lector culto. Sucede lo mismo en la serie $B$ (si no se trata de una misma persona). Al burlarse de los bufones en el infierno, explica Quevedo por qué se hallaba con ellos un juez: "Aquél fue juez maldito, y también está con ellos, pues por dar gusto a todos no hiço justicia, i a los derechos que no hiço tuertos los hiço vizcos". Al margen anotó el lector desconocido de la serie $B$ : "Por hacer a todos gusto, hiço injustos todos sus juicios" (f. 20r). 
Sin embargo, se distingue $B$ de $A$ por el interés que muestra por los chistes, como se observa en cuatro lugares del texto. En cierto pasaje se burla Quevedo de los muchos pasteleros que había en el infierno: "Estauan tantos que andauan dos mil diablos con pisones atacando almas de pasteleros, i aun no bastauan. ‘Ai de nosotros', dijo uno, 'que nos condenamos por el pecado de la carne, sin conocer muger!" Se rió con gusto el lector anónimo de la serie $B$, y comentó al margen: "En esto se parecen los pasteleros a los deuotos de monjas, en condenarse por el pecado de la carne $\sin$ conocer muger" (f. 20v). En otro momento, tras describir su visita al aposento infernal de los bufones, dice Quevedo: "Trabóse una gran pendencia dentro, i el diablo acudió a ver lo que era. lo que me vi suelto, entréme por un corral adelante..." Expresa el mismo lector un juicio sobre la persona de Quevedo, y no del todo favorable: "I no fue poco verse suelto, de no ser metido con los bufones" (f. 20v). Sobre Judas dice Quevedo: "Me puso en duda el conocerle, el decir que fue barbiroxo, como lo pintan los españoles por hacerle estrangero, o barbinegro como lo pintan los estrangeros por hacerle español, porque él me pareció cañón. No es posible menos, ni que tan mala inclinación i ánimo tan doblado se hallara sino en quien por serlo no fuesse hombre ni muger". Agrega el interesadísimo lector: "I no se auría pelado por la frialdad de la estancia" (f. $27 \mathrm{v}$ ). Por último, la sátira contra los escribanos le merece esta nota: "Andan siempre [tachado: de r] con Lúcifer, de ronda y de visita" (f. 29r).

No sabemos de cierto si el propio copista de este ms. fue quien confeccionó las notas de las series $A$ y $B$. Sin embargo, no parece propio que un amanuense estuviera tan familiarizado con la erudición clásica. Antes bien, parece que copiara el amanuense aquellas notas de otro ms. por orden de su patrón. Tampoco sabemos si la serie $B$ se debe a persona distinta que $A$. En todo caso, nos han deparado sus notas a un lector erudito y de mentalidad académica como el autor de la serie $A$; pero menos interesado en corregir errores $\mathrm{y}$, como persona, más capacitado para responder al humor de Quevedo. Heredamos las huellas de una lectura a la que asistieron la sensibilidad y la risa.

En la versión del "Sueño del infierno" que ofrece el mismo ms. que estudiamos, se encuentra un grupo de catorce correcciones al texto, que denominamos como serie $C$. En comparación con la letra del amanuense que copió el texto, ésta es más descuidada, más apresurada, y menos regular. Se nota que las formas de ciertas letras se parecen superficialmente a las de los autógrafos de Quevedo (véanse, lámina 5 , las letras $d, r, t, z$ ); sin embargo, el estudio de unos autógrafos tan seguros como las cartas de Quevedo al Duque 


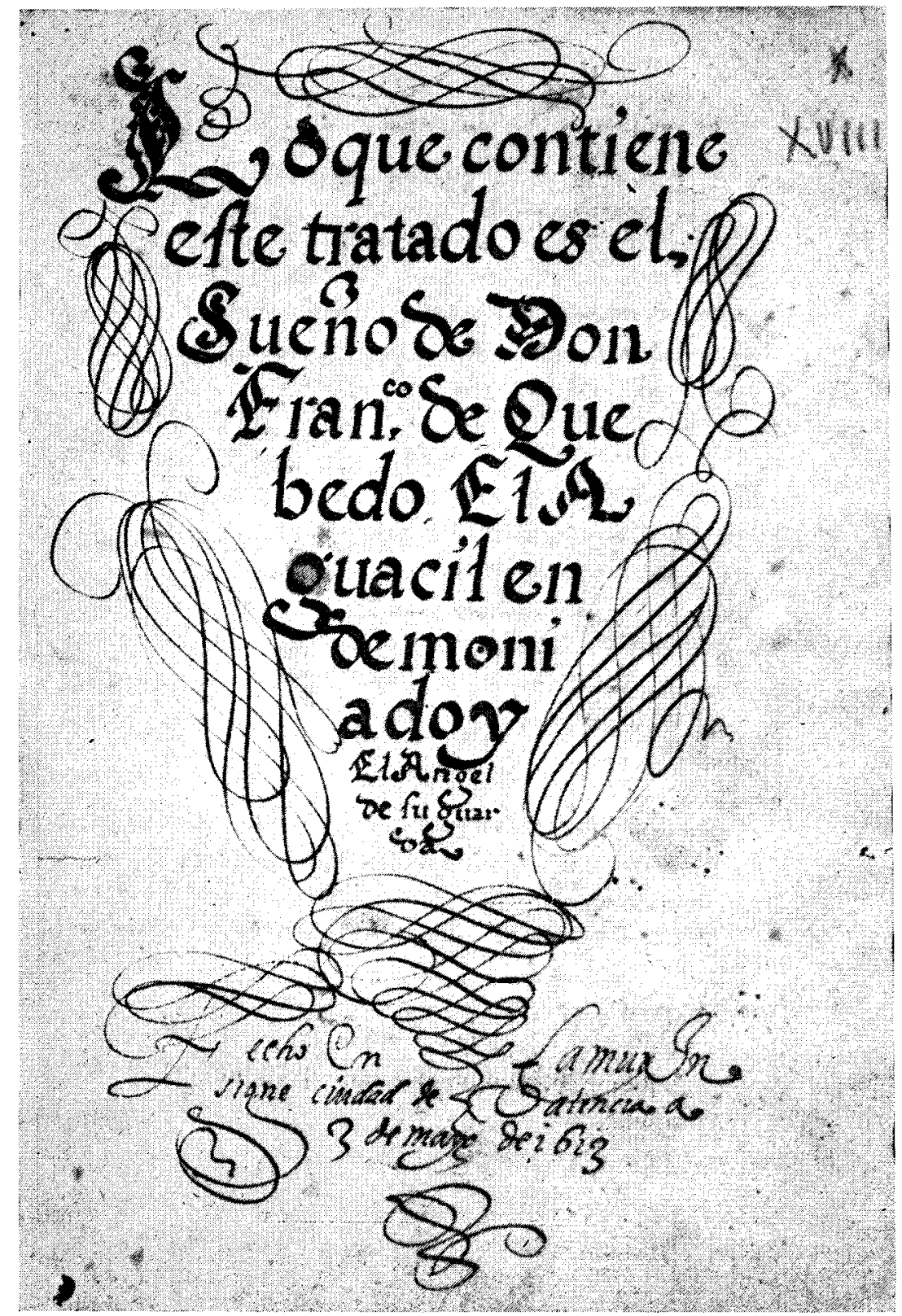

Lámina 1: Ms. 93 de la Biblioteca de Menéndez. Pelayo, f. 1r. Portada del ms., con el lugar y la fecha al pie del folio. 


\section{.1605 \\ Sisoña da queuedo \\ Los icieños sor ilice riomiro que son de Juscter.y oue clíos irbia $y=n$ oro lugur dice, que se a áe crecer que esto es asi quando tour en cosas inportites, o los sueñano. ves, o grades señores como Se colige del admitable Propecto}

Hectu Sperne pys Venuenita Somprea portis Cumpra Veneruns somnia popdus habent.

Digoio o. proposito de que tongo por caydo del culo trno que theice estur nocher pasjacáas haucinálo cerraáo los ojos con el lib. to del ivcato Hupoluto del fin deí.ílumáo, $y$ Segunda bensda de $x_{i} \overline{0}$ lo qual fue Cause de soñae que $D_{c}$ ya el sulcio finel $y$ aung en iasa de in Pocta exa dificultoso ereer que aya cosa de Jusisio aun por Siuños lo husw en nu por la raço que da Claudiario inla pecfoicon alsegundo libro dere. pto. dicuendo que todos los anumaíw sueñe de noche co. Sas como Joinbras de lo que tratan de dia. y Perronio Arbitto Lalo duce

Ct Canis in Somnis leporis Rersigie lartat y hablando de los Jucuse. Ce pauedo cernit Incluso corde P Tribunal

Parecco me oue veya un mançebo, que descurruirdo por el ayce, aaua Vor de Sunliento a ma trópeta a feádo en parte con la fuerça. Su hermofura, hallo el son obe diencia en los marmoles, y oydos en los mucrion. yast al punto enpeso amoucesé toda la tuerra, y dar liciza alos huesos que andauan $\dot{\eta}$ aunos en busca de oteos. ${ }_{i}$ pas

LÁmind 2: El ms. del "Juicio final" que encargó Da Sommala es hoy el ms. Magliabechi VIII.26 de la Biblioteca Nazionale de Florencia, f. 380r. Se observan palabras agregadas por Da Sommaia en las líneas 1 ("1605"), y 2 ("de Queuedo"), y correcciones suyas en las 5 (agrega la $n$ final a "sueñan"), y 16 (corrige el error "perfection", sobrescribiendo "prefation"). No se sabe si la tachadura de la línea 19 se debe al amanuense o al dueño del ms. 


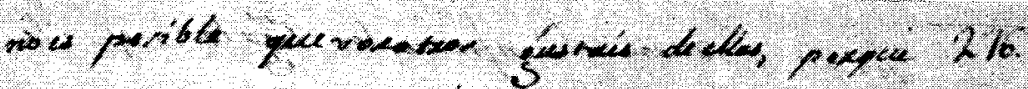

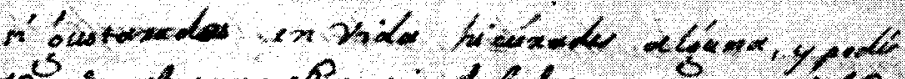

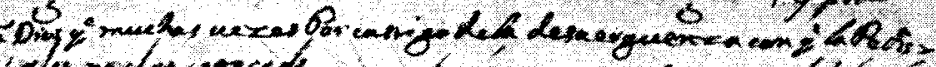

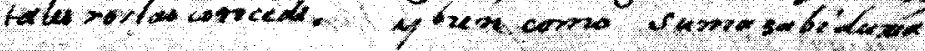

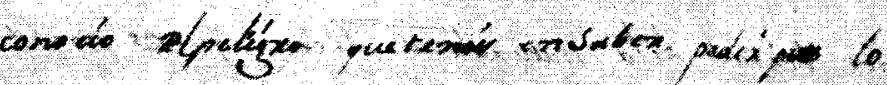

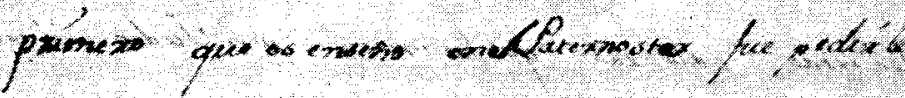

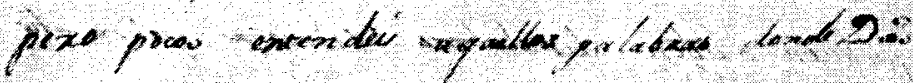

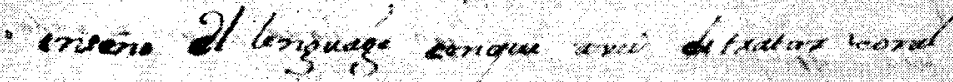

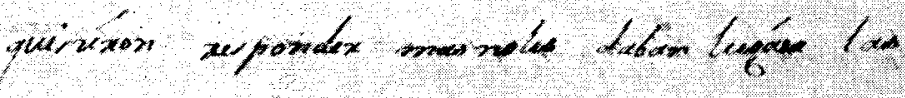

1.

$m+x+\infty \times a$

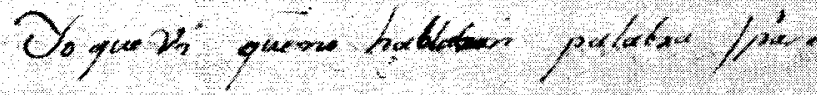

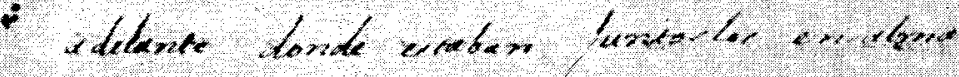

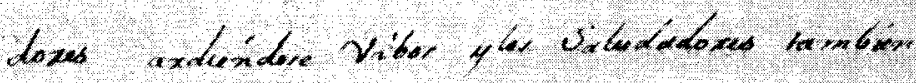

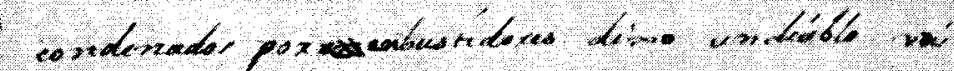

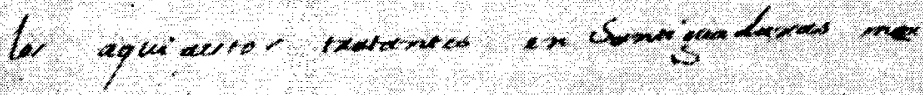

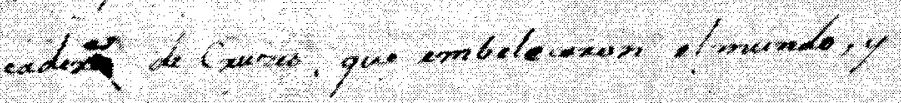

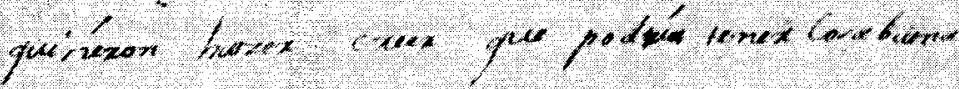

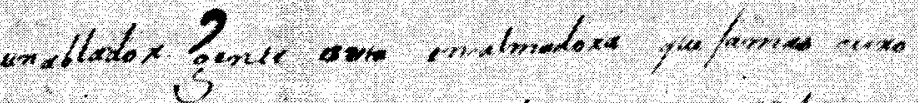

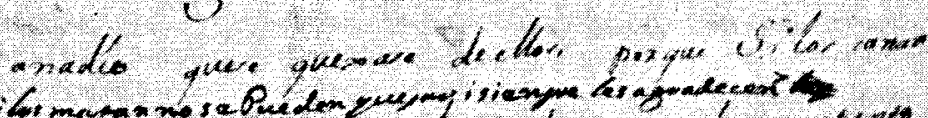

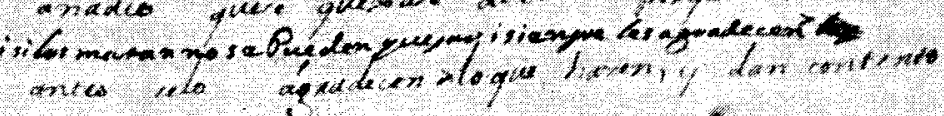

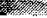

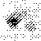

LÁmina 3: El ms. 10387 de la Biblioteca Nacional de Madrid, f. 276r. Se observan correcciones de otra persona que el amanuense, en las líneas 3 (una línea intercalada) ; 6 (intercalar la palabra "el" en la frase "en Paternoster"); 7 (enmendar "aquello" en "aquellas") ; 14 (unir la palabra "enbustidores") ; y 21 (intercalar una línea). 


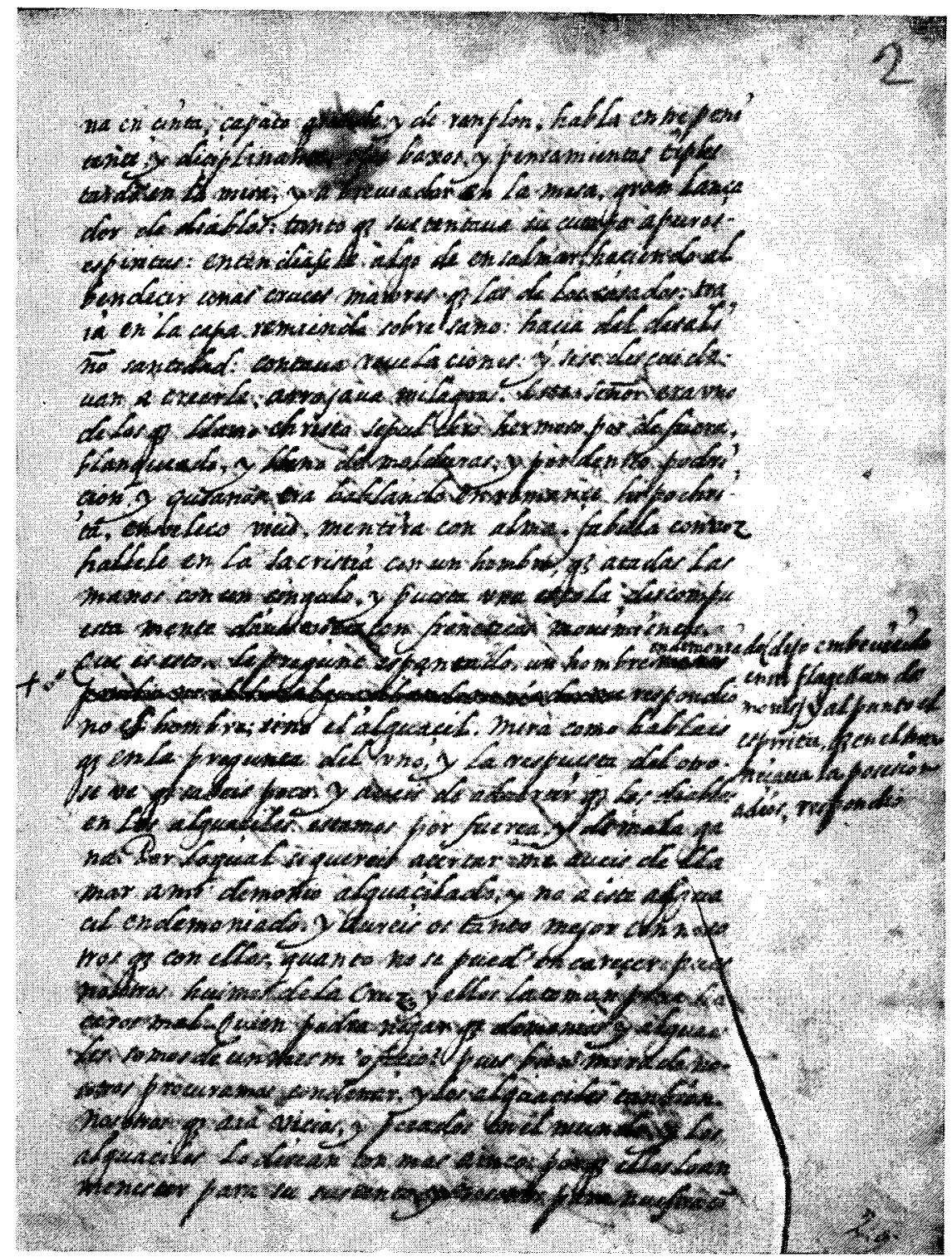

LÁmina 4: Ms. 109 de la Biblioteca de Menéndez Pelayo, f. 2r. Una línea tachada, y el texto correcto suplido al margen, todo por el amanuense (serie $A$ ). 


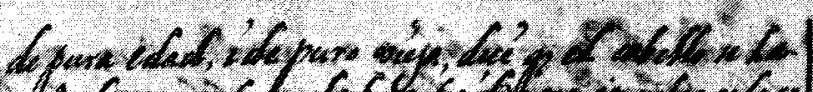

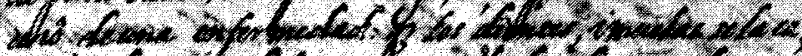

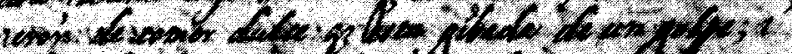

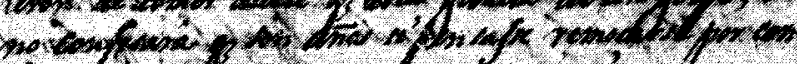

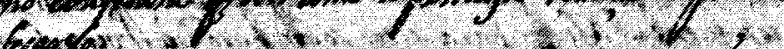

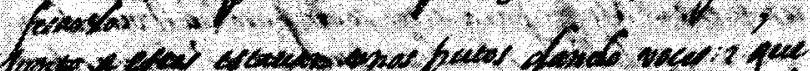

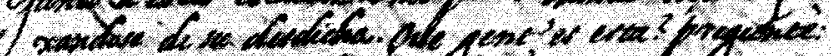

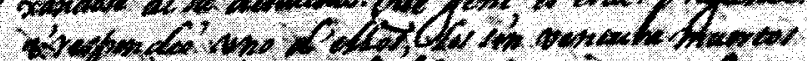

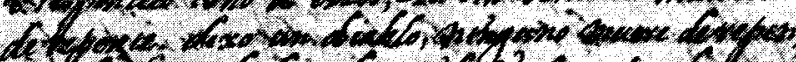

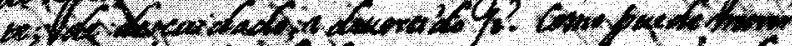

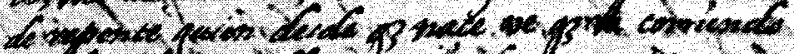

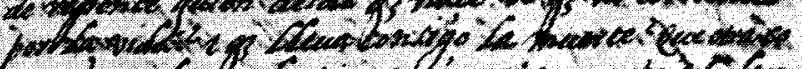

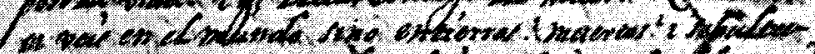

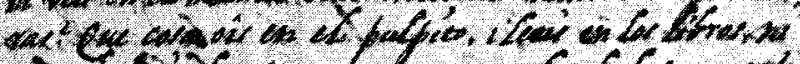

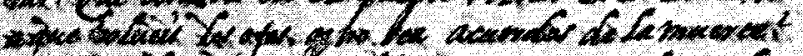

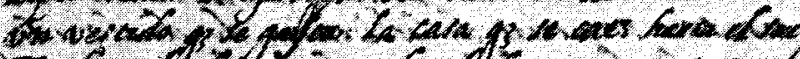

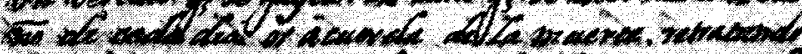

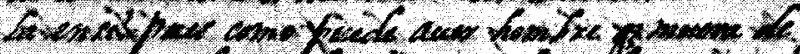

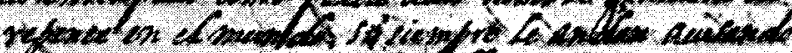

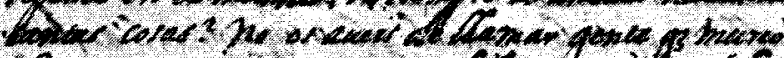

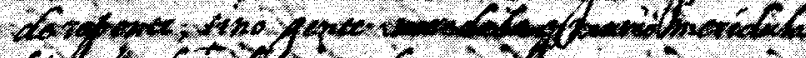

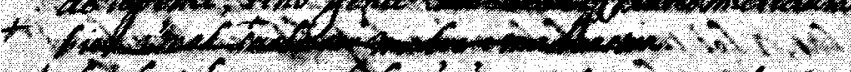

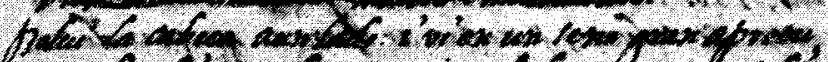

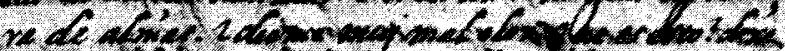

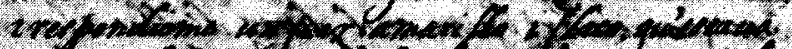

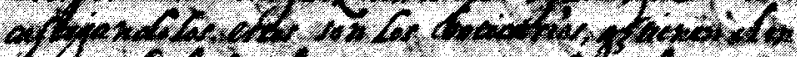

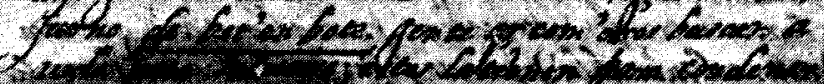

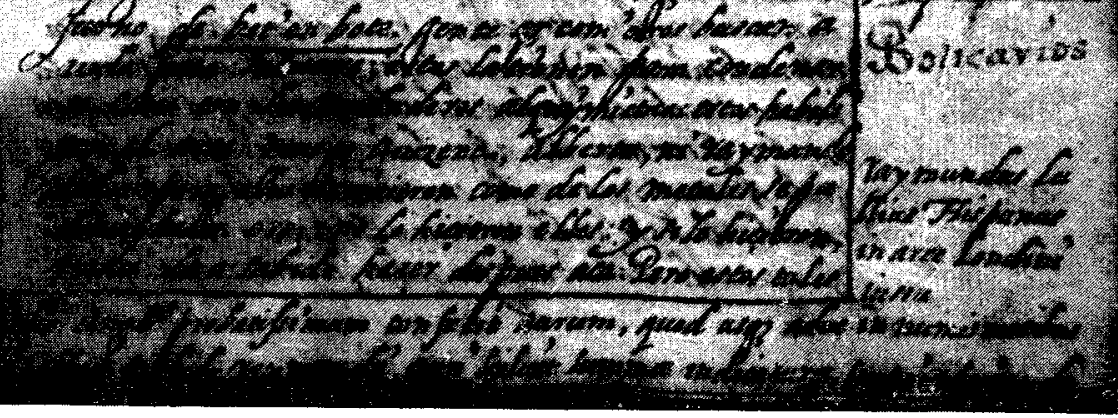

Lámina 5: Ms. 109 de la Biblioteca de Menéndez Pelayo, f. 25r. Se observan dos palabras de la serie E ("Putas", "Boticarios") . Y por encima de la palabra "Boticarios", se ve una nota extensa perteneciente a la serie $C$. 


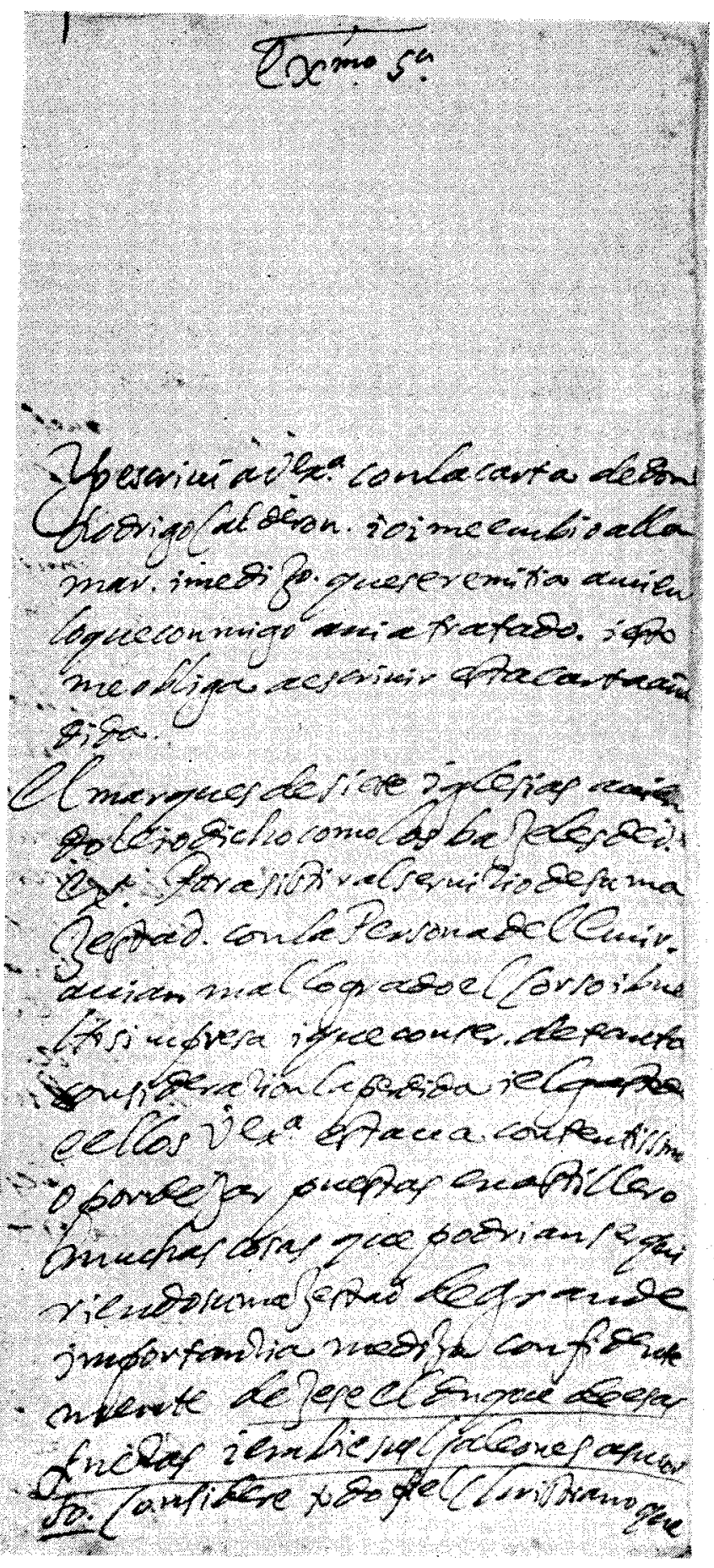

Límina 6: Carta autógrafa de Quevedo al Duque de Osuna, fechada el 1 de abril, 1616. Archivo Histórico Nacional, Madrid, legajo 49866, núm. 45, hoja Ir. 


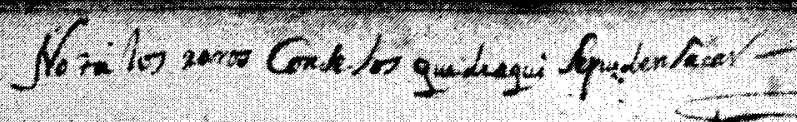

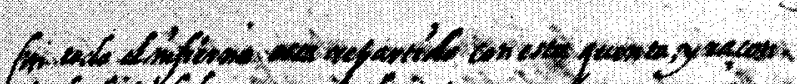

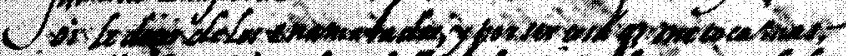

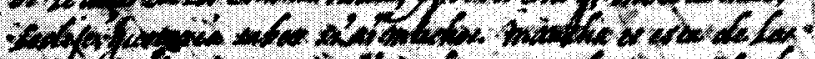

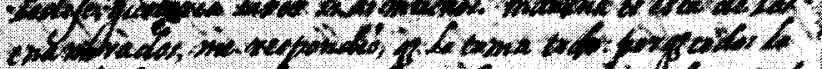

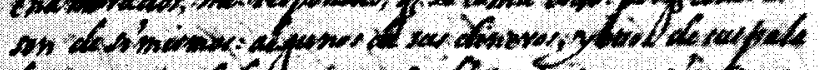

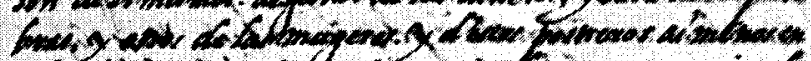

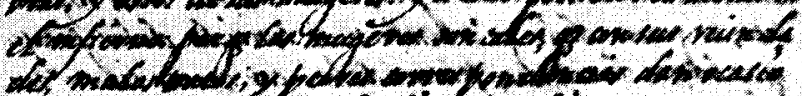

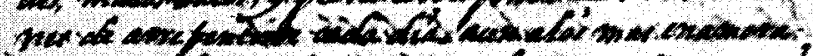

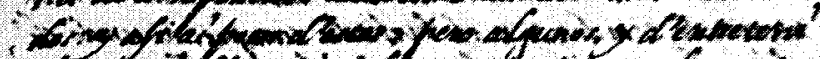

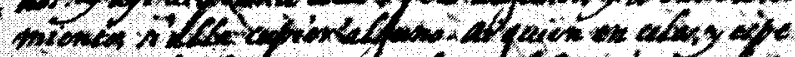

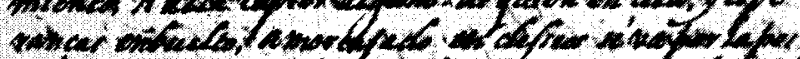

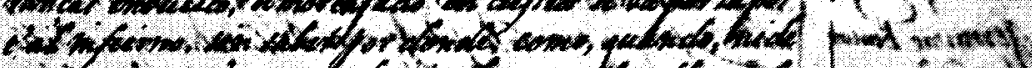

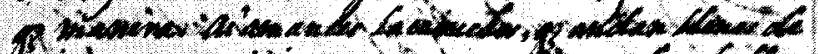

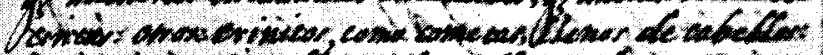

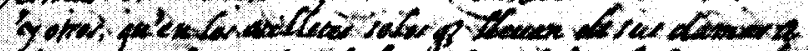

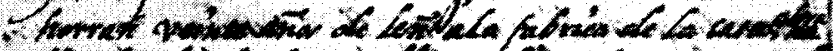
1

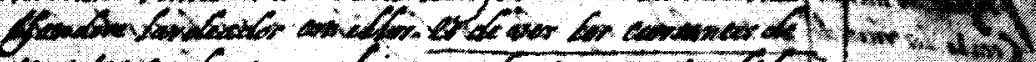

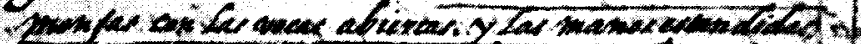
res? 5

\section{$+3$}

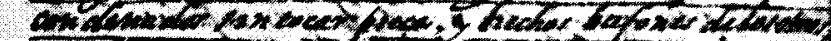

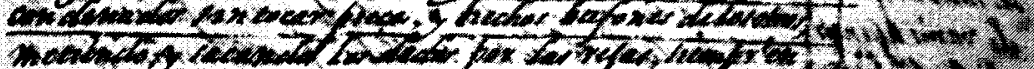

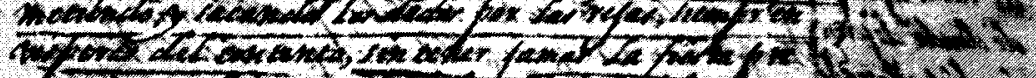

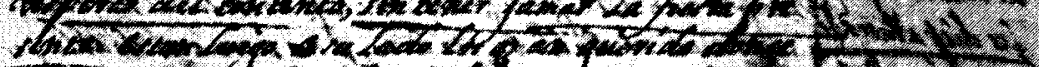

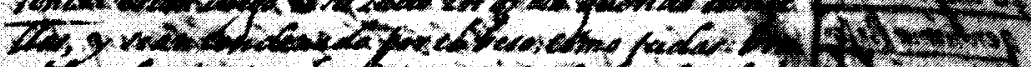

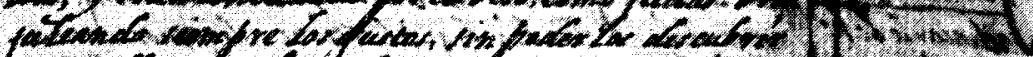

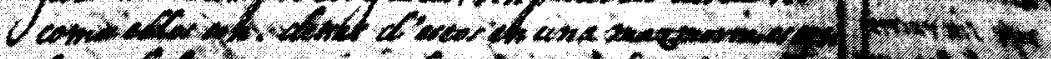

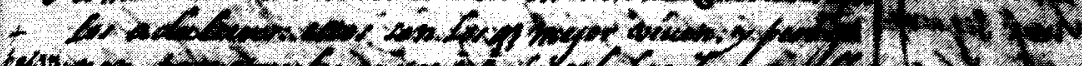

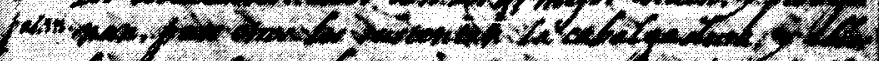
A.

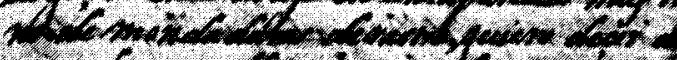

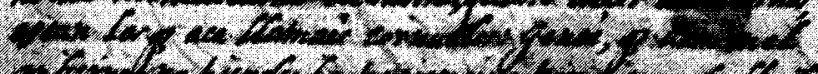

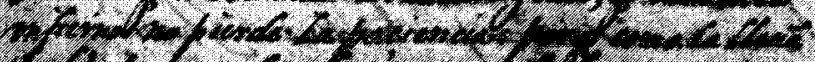

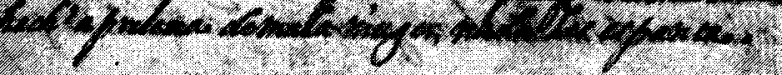




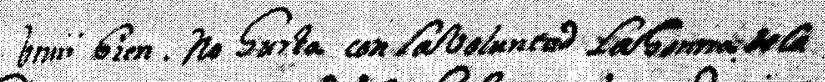

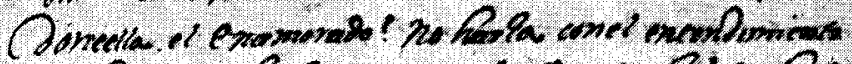

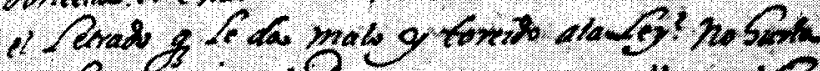

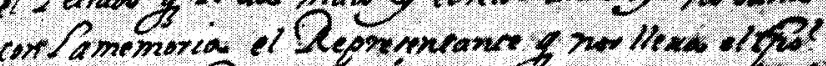

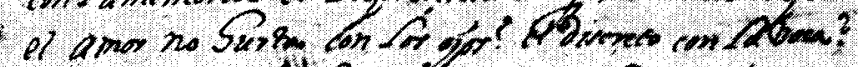

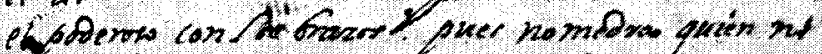

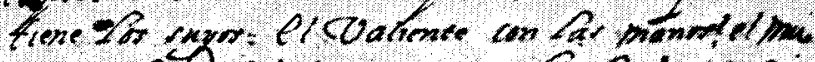

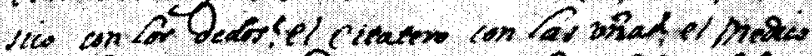

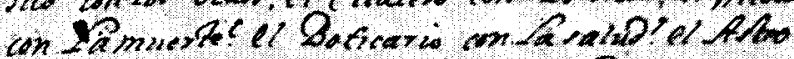

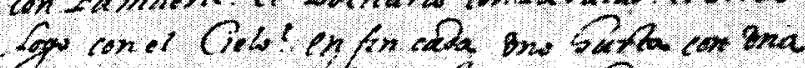

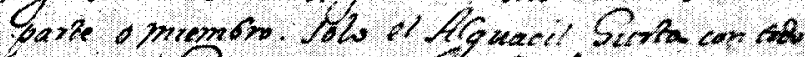

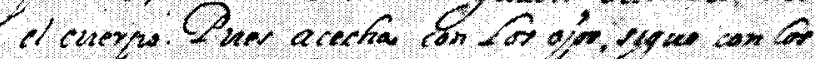

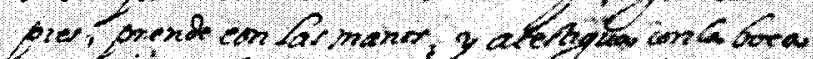

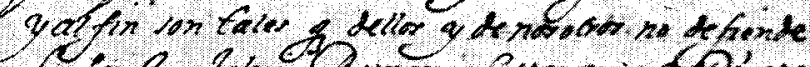

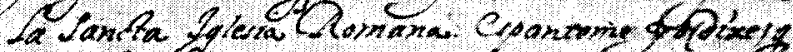

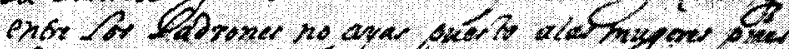

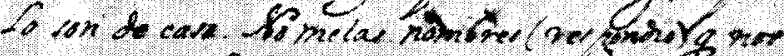

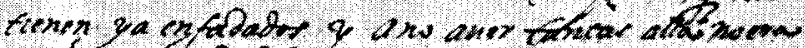

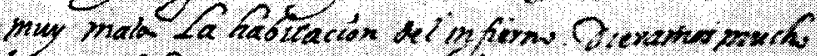

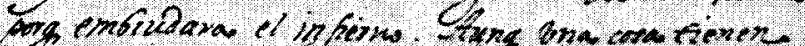

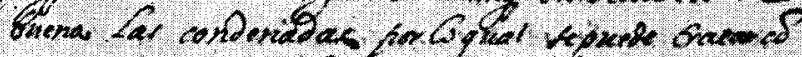

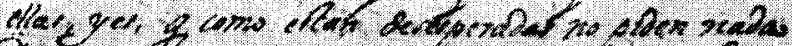

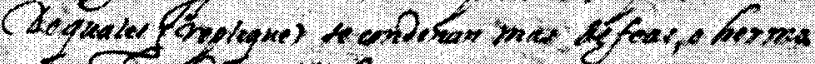

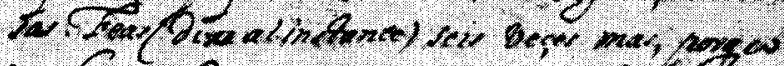

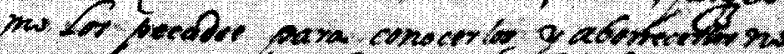

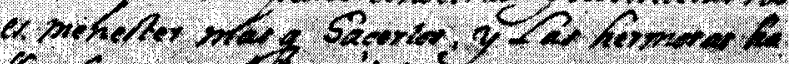

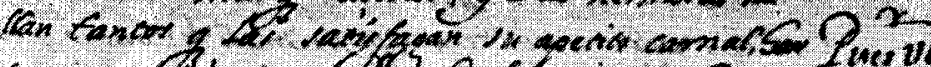

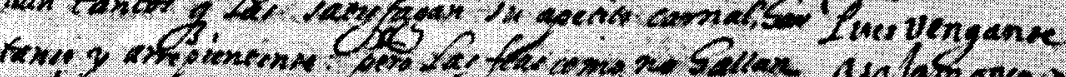

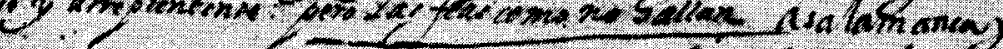
andere. Mrientrand 5 am tore

Lámina 8: Ms. 93 de la Biblioteca de Menéndez Pelayo, f. 16r. Al margen. consejos que de aquí se pueden sacar". 
de Osuna, nos ha revelado otras tantas diferencias caligráficas (véase lámina 6$)$. Y puesto a buscar parecidos, los encontramos con la propia letra del amanuense que copió el texto (letras $d, l, n, q, v$ ). Por otra parte, el contenido de las catorce correcciones no revela precisamente un ingenio comparable al de Quevedo.

Siete de estas enmiendas son breves, adecuadas, y coinciden con los textos de algunos otros mss. Sirva de ejemplo la descripción que sigue de un astrólogo: "Empeçaua a quererlo prouar que él era el astrólogo más cierto; i si dixera puntual, acertara, pues su [tachado: malicia; e interlineado: ciencia] era de punto como calça, sin ningún fundamento" (f. 33r; rezan algunos mss. "ciencia", y otros "sentencia"). Cuando se pregunta a Judas por qué le pintan siempre con botas, responde: "Quisieron significar poniéndome botas que anduue siempre de camino [agregado al margen: para el infierno], i por ser despensero, y así se an de [tachado: imitar; $e$ interlineado: pintar] todos los que lo son" (f. 28v; coinciden los otros mss. con las dos correcciones) ${ }^{7}$. Parece que el corrector tuviese a la vista otro ms. ya que sin tal ayuda no sería fácil coincidir tantas veces, ni acertar con la frase "para el infierno" que no reclama el sentido literal del pasaje.

Pasemos a las siete correcciones que no coinciden con ninguno de los mss. conocidos hoy. Dos son extensas, y adecuadas en el sentido semántico. En un pasaje sobre la gente que pretende disculpar sus pecados alegando la misericordia de Dios, encontró el corrector esta oración en el ms. que tenía delante: "Búrlanse las almas que con sudor la misericordia de Dios conuierten en maldades" (f. 24r) . No lo corrigió según la versión de los otros mss. que conocemos hoy, sino como sigue: "Búrlanse [agregado al margen: a sí propias para maldades] las almas que [tachado: con sudor] la misericordia de Dios convierten en [tachado: maldades; y agregado al margen: lisencia de ofenderle]" 8 .

La segunda de las dos enmiendas mencionadas se encuentra en ciertas palabras que dirige un diablo a la gente que murió difiriendo la oportunidad de arrepentirse. Decía el ms.: "No os auéis de llamar gente que murió de repente, sino gente que murió incrédula bien y mal suele ser madre y madrastra" (f. 25r). Esto lo rectificó el corrector así: "No os auéis de llamar gente que murió de repente, sino gente que murió incrédula [tachado: bien... madrastra, inclusive; y agregado al margen: de que podiades morir

7 De las 7 correcciones mencionadas, las 4 restantes se encuentran en los ff. $32 \mathrm{r}, 32 \mathrm{v}$ (dos), y 33r (otra distinta de la que ya se citó).

8 En los manuscritos que según $\mathrm{mi}$ análisis parecen ser los más autorizados (por cierto mucho más coherentes en sus textos que el manuscrito que examinamos), se lee esta versión: "Se burlan a sí las almas que consideran la misericordia del Señor encubridora de maldades". 
icnorando $[s i c]$ que en vn mismo punto suele la naturaleza ser madre i madrastra. Ex Plinio 7, cap. 50 ㄱ" $^{9}$. Por adecuada que sea la corrección, a la vista de los defectos del ms. que estudiamos, dista mucho de la claridad, la coherencia, el ritmo y la simetría de la versión más autorizada, que a partir de la palabra "incrédula" reza: ". . incrédula de que podía morir ansí, sauiendo con quan secretos pies entra la muerte en la mayor mocedad, y que vna misma ora en dar bien y mal suele ser madre y madrastra". Sin embargo, nos revelan las enmiendas otras dos características del corrector. Primero, que tenía cierta familiaridad con la literatura clásica, o con los manuales de citas clásicas; segundo, que su ortografía dista mucho de ser la de Quevedo (véanse "lisencia" en la corrección anterior, e "icnorando" en la última). Es más: no parece que una persona medianamente culta pudiera escribir la forma "icnorando". Por lo tanto, resulta posible que en la confección de las catorce notas haya intervenido más de una persona, por ejemplo, un erudito y un amanuense, o que las enmiendas procedan de otro ms. cuyo texto se acomodó con mejor o peor fortuna. Pero nuestros datos se limitan a las propias notas, y nos sugieren evitar la especulación.

Las cinco correcciones restantes son adecuadas hasta cierto punto, pero en parte adolecen de falta de sentido. Por ejemplo, en un momento dado se dirige el narrador a la gente que no cumple con sus votos: "¿Qué tempestad no llena de promessas los santos? ¿Y qué bonança tras de ella no las buelue a desnudar con oluido de [tachado: toque de campanas?; y agregado al margen: todo lo pasado?]. Ofrecéis altares en la espantosa cara del golfo, ¿i qué de [tachado: ellos a quitado a los mismos templos; e interlineado: templos a quitado a los mismos la seguridad] [tachado: en; interlineado: de] el puerto" (f. 31r) ${ }^{10}$. El corrector tenía delante de sí un texto con dos deficiencias: la primera ("toque de campanas") acertó a corregir, pero fracasó en la segunda cuando nos ofrece una frase que no entendemos: la seguridad del puerto ha quitado templos a los mismos templos (o a los altares). Sobraba la preposición "en", nada más.

Un ejemplo análogo se encuentra en la sátira contra los que confían de mala manera en la piedad de Dios. Dice un diablo: "Son los que quando hacen algo mal hecho, i se lo reprehenden, pasan adelante y dicen: 'Piadoso es Dios, i no mira en miserias; para esso es la misericordia de Dios.' [tachado: I tanta que con estas demasiar. cllos haciendo mal esperan en Dios, i; al margen s"

IEn fecha posterior fueron cortadas las hojas del manuscrito de manera que hoy faltan la $n$ de la palabra "punto" y la primera a de "madrastra".

10 El encuadernador guillotinó las dos últimas letras de la pálabra "quitado". 
agrega: I mientras ellos confiados con tantas demasías esperan si sea de esperar], nosotros [los diablos] los esperamos acá" (f. 24r) ${ }^{11}$. De nuevo, al intentar corregir un pasaje deficiente, fracasó el corrector creando una frase repetitiva ("esperan... esperar... esperamos") y poco clara ${ }^{12}$.

Al parecer, la persona que incorporó esta serie de anotaciones en el ms. estaba únicamente interesado en corregir el texto de "Infierno". Probablemente tenía a la vista otro ms., pero no sabemos si lo utilizó siempre, ni sabemos si tenía suficiente talento como para corregir esta sátira sin tal ayuda. La presencia de la referencia a Plinio puede responder a la intervención de otra per. sona, o a la utilización de un manual de citas si no es que lo copió del ms. utilizado para enmendar. Merecieron los Sueños lectores más ingeniosos, más sensibles, y con mayor sentido del humor, como veremos en seguida.

En el mismo ms. que examinamos, se encuentran otras dos series de notas, que denominaremos $D$ y $E$. Sus letras respectivas difieren de las de $A, B$ y $C$, y también difieren entre sí. Parecen responder directamente a dos lecturas por distintas personas. En el f. 22r, y otra vez en el $24 r$, repasa y completa el autor de la serie $E$ sendas notas de la $D$, lo cual indica el orden sucesivo de las dos series. De unas 25 notas en cada serie, las dos terceras partes son meras indicaciones de temas ("Pasteleros", "Zapateros", "Libreros", etc.; véase lámina 5). Las restantes se componen de correcciones, subrayados y alguna nota explicativa. Faltan la erudición clásica y la mentalidad académica de $A$ y $B$, como falta el humor de $B$. Apoyan la impresión de un acto rutinario y mecánico, las dos ocasiones en que anota el autor de $E$ un tema sin darse cuenta de que ya estaba señalado en el mismísimo lugar por el de $D$ (ff. $16 \mathrm{r}$ y $18 \mathrm{r}$ ).

En tal contexto destacan dos comentarios valorativos. Al principio del "Alguacil endemoniado" explica un diablo como en el infierno las personas son remitidas a grupos que no parecen guardar una relación lógica con su actividad terrena: "Vn artillero... pidiendo él que le pusieran entre la gente de guerra... fue remitido al quartel de los escríbanos, por ser los que mayores tiros [es decir, engaños] hacen en el mundo. Vn sastre, porque dijo que auía viuido de cortar de vestir [que asimismo es murmurar], fue aposentado con los maldicientes. . O Otro, que dijo que era su oficio enterrar difuntos, fue acomodado con los pasteleros... Vno que

11 Se olvidó el corrector de tachar las palabras "I tanta que... en Dios, i". $Y$ fueron guillotinadas por el encuadernador la última letra de "esperan", y también la de "esperar".

12 De este grupo de correcciones, las tres restantes se encuentran en los ff. $23 \mathrm{r}$, y $34 \mathrm{r}$ (dos). 
vino por unas muertes está con los médicos... Y a un aguador, que dijo auía vendido agua, lo lleuaron con los taberneros". Al margen comenta el autor de la serie D: "Burlas veras" (f. 3v) . A este párrafo del texto, sigue la sátira contra los enamorados, que contiene una serie de imágenes de amantes ridículos. Como queriendo abarcar los dos párrafos, anota a la cabeza de la hoja el autor de $E$ : "Nota los raros consejos que de aquí se pueden sacar" (f. $4 \mathrm{r}$; véase lámina 7 ).

Parece que dos lectores de menos pretensiones eruditas que otros, y con menos sentido del humor, nos confesaran que a ellos les brindaron los Sueños ciertas verdades tan inmediatas y actuales como profundas. Lo que resulta ser la comprobación directa y personal de un valor que habían expresado otros lectores de manera más formal y pública. Por ejemplo, Lorenzo van der Hammen y León, amigo y apologista de Quevedo, al dedicar su edición de los Sueños a Francisco Jiménez de Urrea, le dijo: "Entre todos [los libros escritos por Quevedo] no sé si merecen el primer lugar estos discursos [los Sueños], por su singularidad y artificio, y por aquel primor con que mezcla las veras y la corrección de las costumbres con cosas tan de risa, sin embarazar el donaire el fin principal suyo, que es el bien universal y la mejora de las repúblicas... Luz son para todos ojos... por ir suavizado lo áspero de las verdades con pedazos tan entretenidos como tienen"13. Reconocía el propio Quevedo este valor dual en algunas de sus obras satíricas, pues al enviar La hora de todos a don Alvaro de Monsalve, le dijo en la dedicatoria: "El tratadillo, burla burlando, es de veras. Tiene cosas de las cosquillas, pues hace reír con enfado y desesperación" ${ }^{14}$. Con su acostumbrada concisión e intensidad, precisa Quevedo el sentimiento expresado por Van der Hammen, y por los dos lectores anónimos, cuyas voces comprueban el acierto de la visión del propio autor.

Completan este cuadro valorativo dos comentarios fuertemente humorísticos debidas al lector de otro ms., a quien ofrecian los Sueños una actualidad bien inmediata. Los dos comentarios son de una misma letra, distinta de la del amanuense, y puestos al margen del texto. Por lo tanto, es posible que sean testimonios directos y autógrafos del lector. Cuando se burla Quevedo en el

13 La edición preparada por Van der Hammen se tituló Desvelos soñolientos y verdades soñadas, y fue publicada en Zaragoza en 1627. Citamos por la edición moderna de la versión impresa de los Sueños y discursos que ha hecho Felipe C. R. Maldonado (Madrid, 1972), en la que reproduce la dedicatoria de Van der Hammen (p. 59).

14 Citamos por la edición de Luis Astrana Marín, Obras completas en prosa (Madrid, 1932), p. 226. Hemos comprobado la cita con el manuscrito original, que poseemos. 
"Alguacil endemoniado" de aquellos lindos que "van al infierno con zapatos blancos y de puntillas, informados de que es tierra seca y sin lodos", se le representó al lector una persona real que despreciaba, pues puso al margen: "Como Antonio de Cuéllar, el Procurador de Salamanca". En otra ocasión afirma un diablo que van al infierno muchas más mujeres feas que hermosas: "Las hermosas hallan tantos que las satisfagan su apetito carnal, hártanse y arrepiéntense; pero las feas como no hallan a nadie, allá [al infierno] se nos van en ayunas, y con la misma hambre rogando a los hombres". Al margen palpamos casi la carcajada del lector: "Pues vénganse a Salamanca y no tendrán hambre" (véase lámina 8). Son éstas dos las únicas huellas de una lectura intensamente viva y bien humorada ${ }^{15}$.

James O. Crosby

Florida International University.

15 Se trata del ms. 93 de la biblioteca de Menéndez Pelayo, ff. 16r y $16 \mathrm{v}$ (foliación en números arábigos). 